\title{
Review
}

\section{The Burden of Atherosclerotic Cardiovascular Disease in South Asians Residing in Canada: A Reflection From the South Asian Heart Alliance}

\author{
Kevin R. Bainey, MD, MSc, ${ }^{a, \ddagger}$ Milan Gupta, MD, ${ }^{b, \ddagger}$ Imtiaz Ali, MD, ${ }^{c}$ Sripal Bangalore, MD, ${ }^{d}$ \\ Maria Chiu, PhD, ${ }^{e}$ Kendeep Kaila, MD, ${ }^{f}$ Padma Kaul, PhD, ${ }^{a}$ Nadia Khan, MD, ${ }^{g}$ \\ Kathryn M. King-Shier, RN, PhD, ${ }^{\text {h }}$ Latha Palaniappan, MD, MS, ${ }^{i}$ Guillaume Pare, MD, MSc, \\ Krish Ramanathan, MD, ${ }^{\mathrm{f}}$ Stephanie Ross, MSc, PhD, ${ }^{\mathrm{k}}$ and Baiju R. Shah, MD, PhD ${ }^{1}$ \\ ${ }^{a}$ Mazankowski Alberta Heart Institute, University of Alberta, Edmonton, Alberta, Canada; ${ }^{b}$ Department of Medicine, McMaster University, Hamilton, and Canadian \\ Collaborative Research Network, Brampton, Ontario, Canada; ${ }^{c}$ Department of Cardiac Sciences, Division of Cardiac Surgery, University of Calgary, Calgary, Alberta, \\ Canada; ${ }^{d}$ Division of Cardiology, Department of Medicine, New York University School of Medicine, New York, New York, USA; ${ }^{e}$ Institute of Health Policy, Management \\ and Evaluation, University of Toronto, Toronto, Ontario, ${ }^{f}$ Division of Cardiology, Department of Medicine, University of British Columbia, Vancouver, British Columbia, \\ Canada; ${ }^{g}$ Nursing and Community Health Sciences, University of Calgary, Calgary, Canada, ${ }^{h}$ Department of Medicine, University of British Columbia, Vancouver, \\ Canada $;{ }^{i}$ Division of Primary Care and Population Health, Department of Medicine, Stanford University School of Medicine, Stanford, California, USA; ${ }^{j}$ Department of \\ Pathology and Molecular Medicine, Department of Clinical Epidemiology and Biostatistics, Population Health Research Institute and Thrombosis and Atherosclerosis \\ Research Institute, Hamilton Health Sciences, McMaster University, Hamilton, Ontario, Canada; ${ }^{k}$ Department of Health Research Methods, Evidence, and Impact, \\ McMaster University, Hamilton, Ontario, Canada, ${ }^{l}$ Division of Endocrinology, University of Toronto, Toronto, Ontario, Canada
}

\begin{abstract}
South Asians (SAs), originating from the Indian subcontinent (India, Pakistan, Sri Lanka, Bangladesh, Nepal, and Bhutan), represent one quarter of the global population and are the largest visible minority in Canada. SAs experience the highest rates of coronary artery disease in Canada. Although conventional cardiovascular risk factors remain predictive in SA, the excess risk is not fully explained by these risk factors alone. Abdominal obesity, metabolic syndrome, and insulin resistance likely contribute a greater risk in SAs than in other populations. The South Asian Heart Alliance has been recently formed to
\end{abstract}

Atherosclerotic cardiovascular disease (ASCVD) remains the most common cause of cardiovascular (CV) death worldwide. However, the prevalence of ASCVD and subsequent clinical outcomes can differ by ethnicity. South Asians (SAs) (originally from Bangladesh, Bhutan, Maldives, Nepal, India, Pakistan, or Sri Lanka) are particularly susceptible to the detriments of ASCVD, a phenomenon that cannot be completely explained by conventional $\mathrm{CV}$ risk factors alone. ${ }^{1}$

Received for publication August 12, 2019. Accepted September 25, 2019.

Ethics Statement: The research reported adheres to the relevant ethical guidelines.

${ }^{\ddagger}$ These authors share first authorship.

Corresponding author: Dr Kevin R. Bainey, Mazankowski Alberta Heart Institute, University of Alberta, 2C2.12 WMC, $8440112 \mathrm{St}$, Edmonton, Alberta T6G 2B7, Canada. Tel.: +1-780-407-2176; fax: +1-780-4076452.

E-mail: Kevin.Bainey@albertahealthservices.ca

See page 278 for disclosure information.

\section{RÉSUMÉ}

Les Asiatiques du sud originaires du sous-continent indien (Inde, Pakistan, Sri Lanka, Bangladesh, Népal et Bhoutan) représentent le quart de la population mondiale et constituent la plus importante minorité visible au Canada. C'est aussi au sein de cette population qu'on observe les taux de coronaropathie les plus élevés au Canada. Bien que les facteurs de risque cardiovasculaire classiques conservent leur valeur prédictive chez les Asiatiques du sud, ils n'expliquent pas à eux seuls le risque excédentaire observé. L'obésité abdominale, le syndrome métabolique et l'insulinorésistance constituent vraisemblablement

On behalf of Canada's South Asian Heart Alliance, we gathered the best available evidence to provide expert reflections regarding $\mathrm{CV}$ risk assessment, prevention, and management in SAs as a tool for frontline clinicians.

The South Asian Heart Alliance is a not-for-profit volunteer group of Canadian clinicians and researchers with expertise in the area of cardiovascular disease (CVD) in SAs. The mission of the Alliance is to investigate and recommend the best strategies for the prevention and management of cardiometabolic disease in SAs in Canada. The Alliance did not seek or receive any funding in preparing this article.

\section{Epidemiology of ASCVD in SA Migrants}

South Asia contributes approximately one quarter of the world's population and records the highest global burden of CVD. ${ }^{1}$ Population growth and economic adversity in South 
investigate and recommend the best strategies for the prevention of cardiometabolic disease in SAs in Canada. This topic review represents a comprehensive overview of the magnitude of cardiovascular disease in SAs in Canada, with a review of conventional and novel risk markers in the SA population. Both primary and secondary prevention strategies are suggested and when possible, adapted specifically for the SA population. The need for SAs and their healthcare professionals to be more aware of the problem and potential solutions, along with the need for population-specific research, is highlighted.

Asia have led to an efflux of SAs to other countries contributing to worldwide ethnic diversity. This worldwide migration of SAs (Fig. 1) has allowed standardized comparisons of ASCVD prevalence among SAs. For instance, the prevalence and death rate in specific populations in Canada have been shown to be highest among SAs, followed by Caucasians and lowest in Chinese. ${ }^{2,3}$ In the Canadian Study of Health Assessment and Risk in Ethnic Groups (SHARE) registry, ASCVD prevalence in SAs approached 11\%, far greater than for any other ethnic group studied. ${ }^{3}$

These observations are particularly concerning given that SAs in Canada comprise 1,963,300 inhabitants, constituting $5.6 \%$ of the population-making them the largest visible des facteurs de risque plus importants chez les Asiatiques du sud que dans les autres populations. La South Asian Heart Alliance a récemment été mise sur pied afin d'explorer les stratégies exemplaires pour la prévention des maladies cardiométaboliques chez les Asiatiques du sud au Canada et de formuler des recommandations à cet égard. Cette revue thématique présente un aperçu de l'importance des maladies cardiovasculaires au sein de la population des Asiatiques du sud du Canada, ainsi qu'un résumé des marqueurs de risque classiques et nouveaux dans cette population. Les auteurs proposent des stratégies de prévention primaire et secondaire adaptées, dans la mesure du possible, à la population des Asiatiques du sud. Ils font également ressortir l'importance de sensibiliser davantage les Asiatiques du sud et les professionnels de la santé aux risques et aux solutions possibles, ainsi que la nécessité de mener des recherches axées sur cette population particulière.

minority (Statistics Canada 2016 Census, second largest if including the Aboriginal population) (Fig. 2). Moreover, it is projected the proportion of new SA immigrants will increase expeditiously over time (Fig. 3). Awareness is key, given the residing risk of SAs on the Indian subcontinent having the highest burden of CVD, with CV deaths occurring 5 to 10 years earlier than in other Western nations. ${ }^{4}$ In a large international case-control study of CV risk (INTERHEART), the mean age of presentation for a first myocardial infarction was 52 years in SAs, approximately 10 years earlier than in Caucasians and Chinese. Variation in symptoms and access to care in SAs have been noted. ${ }^{6}$ Developed nations must be prepared to ensure optimal health in SA migrants.

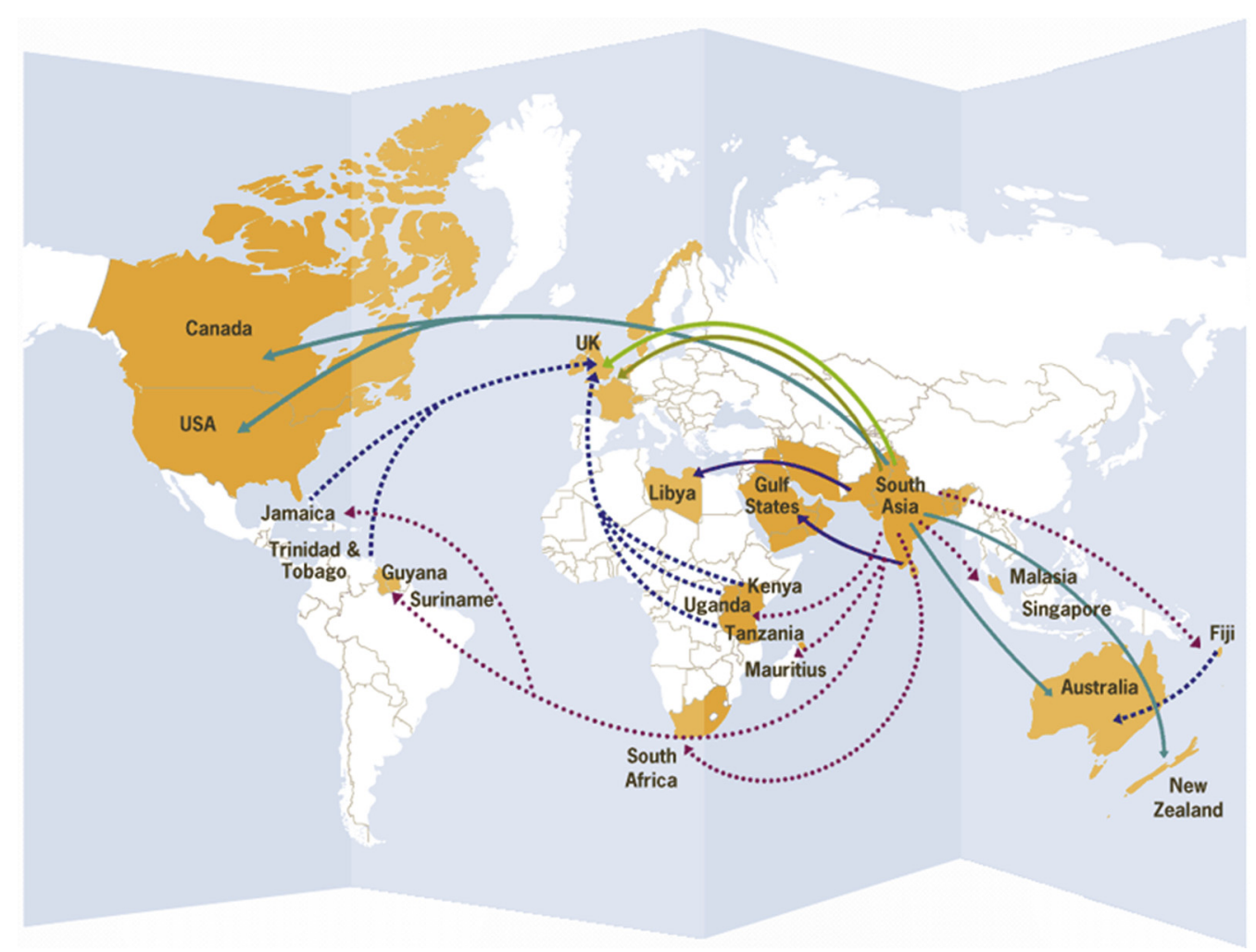

Figure 1. Migration patterns of South Asians (SAs) from the South Asian subcontinent. Reproduced with permission from Anitha S, Pearson R. Striking Women. 2013. Lincoln: University of Lincoln. Available from: www.striking-women.org. 


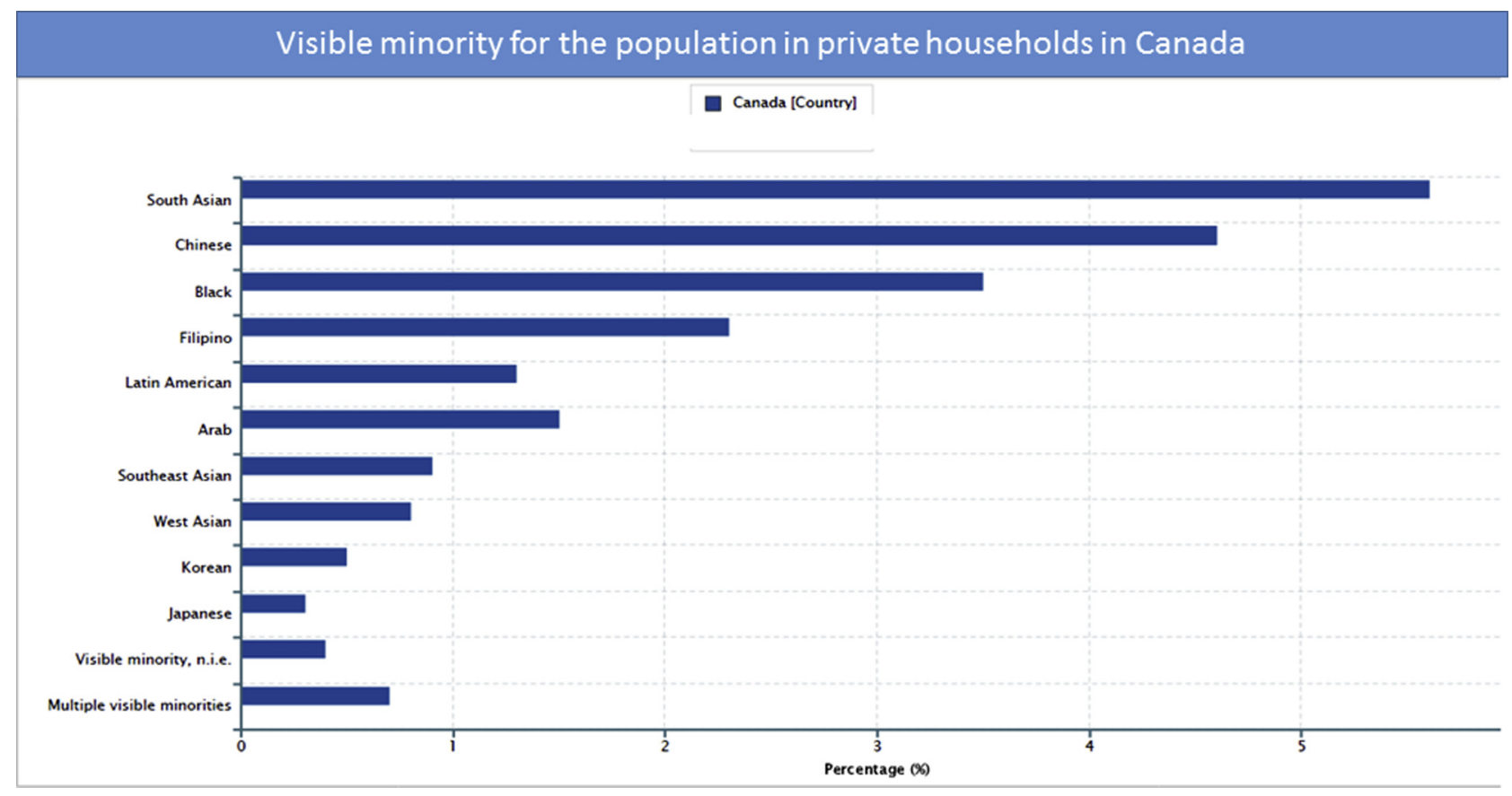

Figure 2. Proportion of visible minorities in Canada according to the population in private households (from Statistics Canada 2016). Reproduced with permission of Statistics Canada.

\section{Risk Factor Profile: Conventional Metrics of Risk}

\section{Diabetes}

More than 80 million adults in South Asia have diabetes, and this number is expected to nearly double by 2045 . Likewise, a high prevalence of diabetes has been observed in the SA diaspora worldwide. SAs living in Canada have a higher prevalence of diabetes than the majority of the Canadian population, with a prevalence of $10 \%$ in SAs compared with $6 \%$ in Caucasians. ${ }^{3}$ Self-reported prevalence of diabetes in the Canadian Community Health Study was doubled in SAs $(8.1 \%)$ compared with Caucasians $(4.2 \%){ }^{8}$ Populationbased healthcare administrative data studies in British Columbia, Alberta, and Ontario have found even higher rates of diabetes among SAs, especially at younger ages. ${ }^{9-11}$ Furthermore, diabetes rates vary within the SA population in Canada, with age-standardized prevalence from $26.8 \%$ among Sri Lankan immigrants to $18.3 \%$ among immigrants from India. ${ }^{12}$

Several reasons for the increased prevalence of diabetes among SAs have been postulated. SAs appear to have higher insulin resistance than other ethnic groups, independent of adiposity. ${ }^{1}$ This increased insulin resistance is noted even in preadolescent children. ${ }^{13}$ In addition, for a given body mass index (BMI), SAs have greater central (abdominal) adiposity, resulting in greater metabolic derangements. There is also evidence that $\beta$-cell function among SAs is inadequate for their degree of insulin resistance. ${ }^{14,15}$ Although a recent meta-analysis found that SAs did not have a greater genetic risk for type 2 diabetes for currently known single nucleotide polymorphisms (SNPs), ${ }^{16}$ future sequencing studies in SA populations may reveal new population-specific alleles. As such, there is general consensus that SAs should be screened earlier for diabetes, especially in the presence of abdominal obesity, dysglycemia, prior gestational diabetes, or a family history of diabetes in a first-degree relative.

\section{Dyslipidemia}

Studies have consistently shown that SAs are more likely to have low high-density lipoprotein cholesterol (HDL-C) and hypertriglyceridemia. ${ }^{17-19}$ Most recently, genetic variants have been identified in SAs (tested in Sikh subjects), increasing the risk of hypertriglyceridemia. ${ }^{20}$ Moreover, this can be driven by insulin resistance in SAs. ${ }^{21}$ Furthermore, even higher HDL-C levels may not be as protective against coronary artery disease among SAs as in other groups. ${ }^{19,22}$ Although low-density lipoprotein (LDL) cholesterol levels are generally similar to or lower among SAs than other populations, at any given LDL-cholesterol level, SAs have a greater risk for coronary artery disease attributed to LDL particle size. ${ }^{19}$ In the INTERHEART study, dyslipidemia was the strongest contributor to acute myocardial infarction (MI) risk among SAs, with a population-attributable risk of approximately $60 \%{ }^{5}$

Canadian studies have confirmed these findings. SAs in Hamilton, Toronto, and Edmonton had lower HDL-C levels. ${ }^{23}$ Likewise, a population-based study found that SA women had lower total cholesterol levels than the general population, but also lower HDL levels. Similar but less marked differences were seen among SA men. ${ }^{24}$

\section{Metabolic syndrome and obesity}

Metabolic syndrome is a cluster of risk factors (impaired fasting glucose, central obesity, dyslipidemia, and 

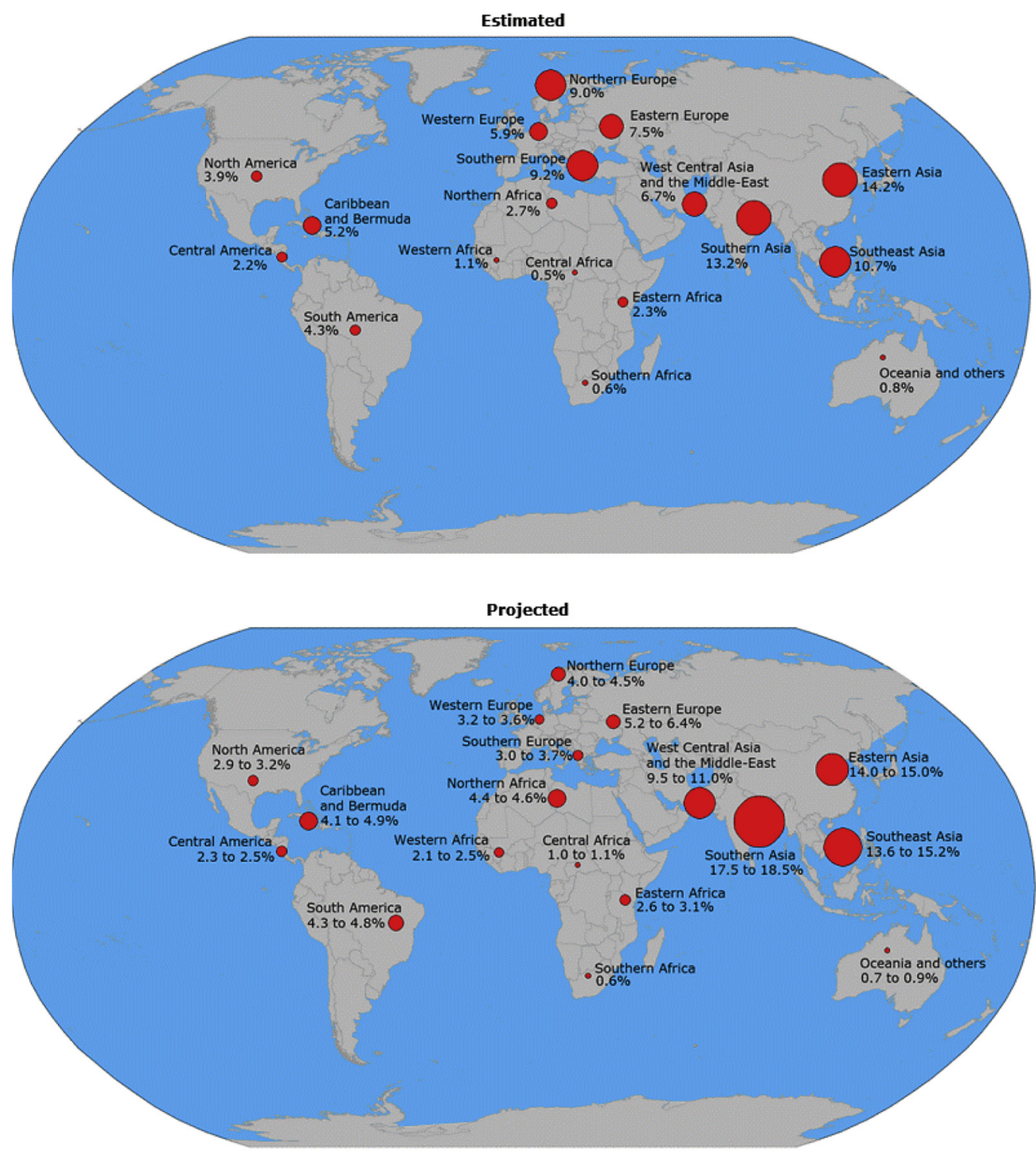

Figure 3. Distribution (in percent) of immigrants to Canada by place birth, 2011 (estimated) and 2036 (projected). The size of the circles is proportional to the distribution of immigrants by birthplace (from Statistics Canada 2016). Reproduced with permission of Statistics Canada.

hypertension) that confers increased risk for ASCVD and is more prevalent in SAs. ${ }^{1}$ The prevalence of metabolic syndrome is increasing among SAs residing on the Indian subcontinent, and in SA migrant communities, it is estimated that $20 \%$ to $25 \%$ of SAs currently have metabolic syndrome. ${ }^{25}$ It has been hypothesized that excess body fat and adverse body fat patterning found in SAs (even at a normal BMI) may contribute to the high prevalence of insulin resistance, which is the underpinnings of diabetes and early atherosclerosis. ${ }^{26}$

SAs have higher risk of diabetes at lower BMI levels compared with Caucasians. ${ }^{8,27}$ Although the standard definition of obesity (BMI $\geq 30 \mathrm{~kg} / \mathrm{m}^{2}$ ) has been validated for Caucasians, the World Health Organization (2011) has recommended lower BMI categories for Asians (underweight $<18.5 \mathrm{~kg} / \mathrm{m}^{2}$, increasing but acceptable risk 18.5 to
$<23 \mathrm{~kg} / \mathrm{m}^{2}$, increased risk 23 to $<27.5 \mathrm{~kg} / \mathrm{m}^{2}$, and high risk $\left.\leq 27.5 \mathrm{~kg} / \mathrm{m}^{2}\right)^{27}$ described as "normal weight obesity." 28 Although evidence validating these cutoff values is primarily available for SAs living in India, ${ }^{29}$ these lower BMI values were also recently adopted by the American Diabetes Association to identify Asian Americans who would benefit from glucose screening. ${ }^{30}$

The International Diabetes Federation has defined lower waist circumference cut points for SA men as $>90 \mathrm{~cm}$ (vs $\geq 94 \mathrm{~cm}$ in Caucasian men). The threshold is $\geq 80 \mathrm{~cm}$ in SA and Caucasian women. Greater central adiposity and greater subcutaneous abdominal adipocyte size have been proposed in the pathogenesis of atherosclerosis and glucose intolerance in SA individuals. ${ }^{1}$ Therefore, it is reasonable to incorporate assessment of BMI and waist circumference in SAs when evaluating risk for ASCVD or diabetes. 


\section{Hypertension}

From population-based analyses in approximately 900,000 Canadians, SAs had a higher incidence of hypertension than Caucasians and developed hypertension at younger ages. ${ }^{31}$ The reasons underlying the higher rates of hypertension are unclear. SAs are less likely to engage in physical activity, have lower daily consumption of fruits and vegetables, ${ }^{32}$ have lower birth weights, which may be associated with increased blood pressure, $^{33}$ and may have underlying impairment of their endothelial vasodilation. ${ }^{34}$

Generally, hypertension care appears to be similar between SAs and Caucasians, and the blood pressure-lowering effect of antihypertensive therapy is similar in SAs as in other groups. ${ }^{35,36}$ The management of hypertension in SAs should follow Hypertension Canada guidelines, with recognition of the higher risk of dysglycemia in SAs when selecting specific drugs. ${ }^{37}$ However, SAs are less likely to adhere to antihypertensive agents compared with Caucasian patients. ${ }^{35}$ In an analysis of death certificate data, there was a greater association between increasing mean arterial blood pressure and stroke in SAs compared with Caucasians in the United Kingdom. ${ }^{38}$

\section{Tobacco}

Although tobacco consumption has been increasing among SA migrants in Europe, Canada, and the United States, it is generally lower compared with other ethnic populations. In the Canadian SHARE registry, the prevalence of smokers was lower in migrant SAs than in European men and was virtually nonexistent in SA women. ${ }^{23}$ As per any ethnic group, complete avoidance of tobacco use and tobacco cessation in smokers are essential to mitigate risk. Culturally specific messaging may be necessary in SAs to mitigate the risk attributable to tobacco use.

\section{Family history of ASCVD}

Family history of ASCVD is a known risk factor for the development of premature coronary disease. However, the impact according to ethnic status is unclear. Recently, data from a large London population-based cohort who completed questionnaires addressing baseline risk with complete coronary heart disease and family history data found a markedly stronger association between family history of ASCVD and the development of clinical (as well as subclinical) coronary disease in SAs compared with Caucasians independent of biologic and socioeconomic risk. ${ }^{39}$ Similar findings have been demonstrated in the Mediators of Atherosclerosis in South Asians Living in America (MASALA) / Multi-Ethnic Study of Atherosclerosis (MESA) cohorts in the United States. ${ }^{40}$ As such, it is important to consider the influence of premature or late-onset family history of ASCVD, particularly in SAs.

\section{Diet}

In a 24-hour dietary recall study of food group intake and the dietary quality of middle-aged and older urban-dwelling Gujarati Asian Indian immigrants $(\geq 45$ years) in the United States, participant diets were fairly adequate in grain and vegetable intake (although fried with ghee) but low in fruits and meats and high in fat (according to guidelines of the US Food Guide Pyramid). ${ }^{41}$ SA men report eating less fruits and vegetables compared with Caucasian men. ${ }^{42}$ The use of oils and ghee and routine use of fried vegetables without intake of "fresh" consumables may be contributory to CV risk and is a modifiable trait that needs to be addressed. Physical activity is suboptimal in SAs. ${ }^{1}$ Given the earlier susceptibility to abdominal obesity and dysglycemia in SA children, dietary considerations must start at a young age. It is reasonable that SAs follow the dietary recommendations put forward in the Canada Food Guide, but future versions of this guide should incorporate traditional SA dietary choices.

\section{Risk Factor Profile: Nonconventional Metrics of Risk}

Population-based studies have shown that although mortality from ASCVD was approximately 60\% higher in SAs than in Caucasians, conventional risk factors alone do not explain this difference. Nonconventional risk factors have been implicated for premature atherosclerosis in SAs. Table 1 highlights the multitude of risk factors in SAs compared with Caucasians, which may contribute to premature atherosclerosis. Although many of these risk markers are of academic interest, most are not yet validated for use in day-to-day practice. In specific cases, some of these markers may assist in risk assessment or decisions for therapy. The novel risk factors are outlined next.

\section{Dyslipidemia beyond usual lipid profile}

HDL-C particle size may be important in the pathogenesis of atherosclerosis. It has been hypothesized that large HDL subclasses $(\mathrm{H} 3+\mathrm{H} 4+\mathrm{H} 5)$ are more efficient at reverse cholesterol transport when compared with small HDL subclass. ${ }^{43}$ Bhalodkar et al. ${ }^{44}$ found that the small HDL-C subclasses $(\mathrm{H} 1+\mathrm{H} 2)$ were significantly higher in Asian Indian men when compared with Caucasian men. ${ }^{44}$

Lipoprotein(a) is considered a special case of genetic contribution to CVD because blood levels are approximately $90 \%$ heritable, and therefore minimally influenced by other nongenetic factors. ${ }^{45,46}$ Additionally, lipoprotein(a) isoform

Table 1. Risk factors in South Asians compared with Caucasians

\begin{tabular}{llc}
\hline \hline Risk marker & \multicolumn{1}{c}{$\begin{array}{c}\text { Potential } \\
\text { mechanism }\end{array}$} & $\begin{array}{c}\text { Contribution SAs } \\
\text { vs Caucasians }\end{array}$ \\
\hline Diabetes/dysglycemia & Multiple & $\uparrow$ \\
Hypertension & Multiple & $\uparrow$ or $\leftrightarrow$ \\
LDL-C & Direct & $\leftrightarrow$ \\
HDL-C & Unknown & $\uparrow$ \\
Triglycerides & Unknown & $\uparrow$ \\
Abdominal obesity & Multiple & $\uparrow$ \\
hsCRP & Vascular Inflammation & $\uparrow$ \\
Adiponectin & Multiple & $\uparrow$ \\
Lp(a) & Atherothrombosis & $\uparrow$ \\
Genetics & Multiple & $?$ \\
Diet & Multiple & $\uparrow$ \\
Physical activity & Multiple & $\uparrow$ \\
Lipid particle size & Direct? & $\uparrow$ \\
PAI-1/fibrinogen & Thrombosis & $\uparrow$ \\
Fetal origins & Multiple & $\uparrow$ \\
\hline
\end{tabular}

$\uparrow$ indicates greater risk contributor in South Asians. $\leftrightarrow$ indicates similar risk contributor in South Asians and whites.

HDL-C, high-density lipoprotein cholesterol; hsCRP, high-sensitivity Creactive protein; LDL-C, low-density lipoprotein cholesterol; Lp(a), lipoprotein a; PAI-1, plasminogen activator inhibitor 1. 
size is inversely associated with CVD risk, where patients with smaller isoforms have a greater risk of CVD compared with those with larger isoforms. ${ }^{47}$ Several studies have observed higher mean levels of lipoprotein(a) in SAs relative to other ethnic populations. ${ }^{48-57}$ Saleheen et al. ${ }^{58}$ performed a Mendelian randomization to explore the causal effects of lipoprotein(a) and isoform size on CVD in 17,503 patients from the Pakistan Risk of Myocardial Infarction Study (PROMIS). ${ }^{58}$ The authors reported that a 1 standard deviation increment in lipoprotein(a) concentration was associated with an increased risk of MI after adjusting for the LPA KIV2 repeats and conventional lipids. ${ }^{58}$ Overall, this study demonstrated that small lipoprotein(a) isoform size and increased lipoprotein(a) concentrations are independent causal risk factors for CVD. ${ }^{58}$ Of note, a comparison of 6 major ethnic groups (ie, Africans, Arabs, Europeans, Latin American, SAs, and Southeast Asians) from the INTERHEART study revealed that lipoprotein(a) has the highest population attributable for MI risk in SAs. Measurement of lipoprotein(a) may be considered in SAs with premature (unexplained) ASCVD or in those with a particularly strong family history of premature ASCVD. In such cases, an elevated lipoprotein(a) level may warrant intensification of LDL-lowering treatment and lifestyle measures. Specific pharmacologic/biologic inhibitors of lipoprotein(a) are currently under investigation.

\section{Thrombogenic risk factors}

Plasminogen activator inhibitor type 1 (PAI-1) inhibits the effect of plasminogen activators, thereby inhibiting plasmin formation and downregulating breakdown of fibrin clots. This decreased endogenous fibrinolytic activity may be responsible for increased risk of thrombosis including reinfarction. Mendelian randomization studies have shown a causal association between PAI-1 and coronary heart disease. ${ }^{59}$ Studies have shown that SAs have increased levels of PAI-1. 3,60

Studies have also shown that SAs have greater levels of other prothrombotic factors, such as fibrinogen levels. ${ }^{3}$ In addition, some studies have shown higher platelet reactivity in SAs with diabetes and ASCVD when compared with SAs without 1 or both conditions. ${ }^{61}$

\section{Inflammation}

C-reactive protein (CRP) has been shown to be a predictor of ASCVD, albeit a known marker of vascular inflammation. CRP enhances LDL aggregation, increases vascular cell adhesion molecules, and has been implicated in plaque vulnerability. Studies have shown that SAs have higher levels of CRP than Caucasians, and this has been mainly attributed this to the high prevalence of abdominal obesity in SAs. ${ }^{62}$ Abdominal adipose tissue is a major source of cytokines, including interleukin-6, a determinant of hepatic CRP synthesis. CRP can be assessed in moderate-risk SAs to assist decision-making regarding the need for lipid-lowering therapy.

\section{Genetic polymorphisms}

Genome-wide association studies (GWAS) have sought to identify common genetic determinants of CVD and to explore the genetic burden in multi-ethnic populations. ${ }^{63}$ The Coronary Artery Disease (C4D) Genetics Consortium conducted a GWAS in 8424 Europeans and 6996 SAs with ASCVD and 15,062 controls. ${ }^{64}$ The authors identified several SNPs associated with ASCVD in European and SA patients, but there were no marked differences in the effect sizes between the 2 ethnic groups. Furthermore, the INTERHEART genetic study assessed whether a genetic risk score, composed of 25 ASCVD-related SNPs, was associated with the risk of MI in 8795 individuals of European, SA, Arab, Iranian, and Nepalese origin. ${ }^{65}$ The genetic risk score was associated with a minimal 6\% increase in the risk of MI after adjusting for demographic and modifiable factors with no heterogeneity among ethnic groups.

With the higher prevalence of diabetes in SAs, Morris et al. ${ }^{66}$ conducted a large GWAS in 34,840 type 2 diabetes cases and 114,981 controls (which included a subset of 1178 cases and 2472 controls of Pakistani descent subjects) and found no heterogeneity across different ethnic groups. ${ }^{66}$ Another large meta-analysis showed that there was no difference in risk per allele between ethnic groups for common SNPs associated with the risk of diabetes in the European or SA cohorts, but there were large differences in allelic frequencies across groups. ${ }^{16}$

The genetic differences observed in SAs and other ethnic subgroups may be largely driven by differences in risk allele frequencies. Despite some striking examples, insufficient genetic knowledge exists to fully account for prevalence differences between populations. There is also little evidence to support differences in allelic odds ratios across ethnic groups. Thus, a better understanding of the genetic mechanisms and biological pathways of CVD will help to distinguish the differences in disease risk across ethnic groups due to genetic factors and differences in lifestyle.

\section{Gestational Diabetes in SAs}

There is increasing evidence to suggest that pregnancy complications and outcomes are a prognostic indicator of the long-term risk of CVD in the mother and the offspring. Therefore, current guidelines categorize women with a history of gestational diabetes mellitus (GDM) to be at risk for CVD. ${ }^{67}$ Canadian population-based analyses have shown that the prevalence of GDM among SA women is double that among the general population: Rates of $8.4 \%, 13.9 \%$, and $7.7 \%$ have been reported in pregnant women of SA ethnicity in Alberta, British Columbia, and Ontario, respectively, compared with $4.2 \%, 5.8 \%$, and $3.3 \%$ in the general population of pregnant women in the 3 provinces, respectively. ${ }^{68,69}$ In the South Asian Birth Cohort (START) in Ontario, the age-standardized rate of GDM was $40.7 \%$ among the 1012 SA women with singleton pregnancies. ${ }^{70}$ The study found that potentially modifiable risk factors, such as pre-pregnancy weight and low diet quality, accounted for $37 \%$ of the population attributable risk of GDM in this population.

Although GDM is generally a temporary condition and resolves postpartum, it is an established risk factor for the subsequent development of type 2 diabetes. In the MASALA study, women with a history of GDM had a 3-fold increase for developing type 2 diabetes compared with women without GDM with increase in CVD. ${ }^{71}$ Further studies in different countries support these findings in SA migrants. ${ }^{72-74}$ Finally, 
newborns of SA mothers with GDM have increased birth weight and body fat with reduced insulin sensitivity, which conceivably could predispose toward adiposity and type 2 diabetes in adult years. ${ }^{70}$ Therefore, it is suggested that SA women with a history of gestational diabetes undergo periodic $\mathrm{CV}$ and diabetes risk assessment, regardless of age.

\section{Primary Prevention Strategies}

Effective primary prevention requires identifying at-risk individuals to initiate selective diagnostic and treatment interventions to lower risk, because this strategy is more efficient than whole population approaches. Although SA populations are collectively at increased risk for developing CVD, there is a heterogeneous risk profile within these groups. However, summative $\mathrm{CV}$ risk assessment tools were largely derived from non-SA populations and as such may not be generalized to SAs given that risk level and risk factors may differ between (and within) ethnic groups.

A recent systematic review examined the predictive accuracy of global CV risk assessment tools in adult SA populations: The Framingham 10-year CV risk model, the modified Framingham 10-year CV risk tool, the UK Prospective Diabetes Study (UKPDS) score, and the QRISK2 model all showed an increased risk score was associated with higher CV events. However, 3 of the 4 models still underestimated risk in SAs. ${ }^{75}$ From this systematic review, only 1 study reported measures of model performance; both the modified Framingham 10-year CV risk model and the QRISK2 model had the best discrimination in SAs (better in men than in women). ${ }^{76}$ The modified Framingham risk score (advocated by the United Kingdom) applies a correction factor to the Framingham risk score in SAs. ${ }^{7,78}$ Other scoring algorithms, including the ETHRISK score, American College of Cardiology/American Heart Association ASCVD, score, and Reynolds score, have yet to be independently validated in SA populations. Most recently, coronary artery calcium scoring for coronary artery disease incidence and progression may be of greater utility in SAs (particularly men) compared with other ethnic groups in those in whom underlying risk may be indeterminate. ${ }^{75}$ Ideally, when assessing ASCVD risk in SAs, a risk score should be used that has been validated in SAs residing in Canada. In the absence of such data, a correction factor of 1.4 to 1.6 can be applied to the modified Framingham risk score to estimate actual risk in SAs, based on observations in the United Kingdom.

\section{Secondary Prevention Strategies}

\section{Pharmacotherapy}

Although the efficacy of dual-antiplatelet therapy has been widely established for ACS, studies were performed mainly in Caucasians. ${ }^{80-82}$ It is largely unknown whether the efficacy and safety of dual-antiplatelet therapy are similar in SAs. It is of interest to note the gain-of-function CYP2C19 polymorphism * 17 allele produces higher levels of the active thiol metabolite compared with noncarriers, resulting in a greater antiplatelet effect and an increased risk of bleeding. In a clopidogrel pharmacogenetics analysis of East, South, and other Asian populations, there is an increased prevalence of this allele among subjects of SA descent (28\%) in comparison with subjects of East Asian (2\%) and Austronesian descent (5\%). ${ }^{83}$ The efficacy and side-effect profile of statins among SAs appear to be similar to those of Caucasians (LDL reduction of $30 \% / 39 \%$ with $10 \mathrm{mg} / \mathrm{d}$ of atorvastatin and $40 \% / 44 \%$ reduction with $10 \mathrm{mg} / \mathrm{d}$ of rosuvastatin). ${ }^{84,85}$ Other preventative strategies have not been specifically studied in SAs; thus, all evidence-based pharmacotherapies should be applied equally to SAs as per national guidelines. In the future, SAs should be better represented in major clinical trials to verify optimal treatments and dosing strategies, and awareness efforts amongst the SA community may be helpful in this regard.

\section{Revascularization}

In a large Canadian observational study, revascularization of any type (coronary artery bypass grafting [CABG] or percutaneous coronary intervention) was associated with improved survival in propensity-matched patients $(18 \%$ lower risk of mortality) at a median of 64 months in SAs compared with Caucasians presenting with ACS. ${ }^{86}$ Furthermore, even undergoing diagnostic coronary angiography itself resulted in improved rates of optimal medical therapy use among SAs. It is of interest to note the baseline burden of coronary disease in those receiving cardiac catheterization was higher in the SAs (even after baseline adjustment). ${ }^{86}$ In a cohort of patients with acute MI, SAs had similar rates of revascularization (and no difference between the use of CABG and percutaneous coronary intervention) but had an overall 35\% lower risk of long-term mortality compared with Caucasians despite a higher rate of 3-vessel coronary disease demonstrated in SAs. ${ }^{87}$ When evaluated for all revascularization procedures regardless of presentation, mortality during longer-term follow-up was significantly lower in SAs $(24 \%$ lower risk compared with other Canadians). ${ }^{88}$ In a large Canadian cohort of propensity-matched patients undergoing CABG, SAs had a higher freedom from major adverse cardiac or cerebrovascular events (defined as all-cause death, MI, stroke, or coronary reintervention ( $9 \%$ lower risk) driven by a $19 \%$ lower risk of all-cause mortality compared with the general population (mostly Caucasians) (mean follow-up 9.1 years). ${ }^{89}$ Given the culmination of these data collected in a Canadian population, revascularization should be strongly considered in SA patients.

\section{Cardiac rehabilitation}

The merits of cardiac rehabilitation have been widely established for secondary prevention. However, to our knowledge there have been no prior studies evaluating the effect of cardiac rehabilitation in SAs with established ASCVD. In a large study of Canadian patients with angiographically confirmed ASCVD, 50.6\% of SAs attended cardiac rehabilitation (compared with $43.0 \%$ of Caucasians). ${ }^{90}$ Overall, CR was associated with long-term survival irrespective of ethnic group total study population. However, when comparing SAs vs Caucasians attending CR, improved survival was observed in SAs, which appeared limited to SAs who completed CR. ${ }^{90}$ These data would strongly support participation in cardiac rehabilitation programs for SAs given the incremental benefits and association with improved longterm survival. 


\section{Physical activity}

SAs in Canada are more sedentary and less likely to engage in vigorous physical activity than their non-SA counterparts. Having low physical activity was associated with greater diagnosed depression in $\mathrm{SAs}^{37}$ and is associated with increased risk of CVD. Limited understanding of the role of exercise in preventing CVD, lack of time, competing priorities against family time or work, and for women, perceived lack of safety and lack of exercise facilities catering to women were barriers to engaging in physical activity in SAs. Several trials identified $\mathrm{CV}$ benefits of increased physical activity in SAs, which include preventing or delaying onset of type 2 diabetes, reducing weight, lowering blood pressure, and improving clinical outcomes in those with established diabetes. ${ }^{91,92}$ Accordingly, statements such as the Canada Physical Activity Guidelines were established with recommendations. ${ }^{40}$ Although the type and dose of physical activity to optimally engage the community and reduce $\mathrm{CV}$ risk for SAs are unknown, SAs are more likely to walk or use housework to be physically active and less likely to engage with sports. ${ }^{93}$ Bollywood dancing among those with diabetes was also associated with a reduction in hemoglobin Alc and weight, suggesting the beneficial role of culturally appropriate exercise strategies to engage SAs to improve physical activity. ${ }^{94}$

\section{Future Research}

Given the population size and the inherent risk in SAs in Canada, it is incumbent upon society to invest resources and expertise to better understand the determinants and optimal management of ASCVD in this high-risk community. Most recently, other societies have also expressed concerns regarding risk of ASCVD in this ethnic community. ${ }^{95,96}$ As it stands currently, much effort has gone into the investigation of both conventional and nonconventional risk factors in SAs. Addressing these risks could curtail the detriments of atherosclerosis. However, further investigation of risk and ethnic-based targeted therapy are required. Genetic markers of risk are paramount and need to be identified according to ethnic group. A greater appreciation and understanding of ethnic-specific metabolomics as biologic markers of risk are needed to identify SAs who may truly benefit from primary preventative measures and strategies. Additionally, pharmacotherapy needs be tailored according to ethnic origin in the era of precision medicine; however, further investigation into varied differences in pharmacokinetics are required to appreciate altered effects on safety and efficacy. Ultimately, prevention is the best medicine, and substantial resources need to be invested in identifying strategies to ensure that SAs live the healthiest lifestyle possible, essentially from birth. ${ }^{82}$

\section{Conclusion}

Given the increased mortality of SAs with ASCVD, optimal management of risk factors according to evidencebased targets and intense lifestyle modification are paramount to reduce the ASCVD burden in this high-risk patient population. Pending additional research to guide therapy and prevention, aggressive implementation of prevention measures, and structured management algorithms are urgently needed for reducing the ASCVD burden among SAs living abroad.

\section{Secondary Reviewers}

Arun Garg, MD (Vancouver, BC), Arvinder Grover, MD (Toronto, ON), Anmol Kapoor, MD (Calgary, AB), Gavin Oudit, MD (Edmonton, AB), Kiran Patel, MD (Birmingham, UK), Jay Shavadia, MD (Saskatoon, SK), Narendra Singh, MD (Atlanta, GA), Koon Teo, MD (Hamilton, ON), Kris Vijay, MD (Scottsdale, AZ)

\section{Disclosures}

The authors have no conflicts of interest to disclose.

\section{References}

1. Bainey KR, Jugdutt BI. Increased burden of coronary artery disease in South-Asians living in North America. Need for an aggressive management algorithm. Atherosclerosis 2009;204:1-10.

2. Sheth T, Nair C, Nargundkar M, Anand S, Yusuf S. Cardiovascular and cancer mortality among Canadians of European, south Asian and Chinese origin from 1979 to 1993: an analysis of 1.2 million deaths. CMAJ 1999;161:132-8.

3. Anand SS, Yusuf S, Vuksan V, et al. Differences in risk factors, atherosclerosis, and cardiovascular disease between ethnic groups in Canada: the Study of Health Assessment and Risk in Ethnic groups (SHARE). Lancet 2000;356:279-84.

4. Reddy KS. Cardiovascular disease in non-Western countries. N Engl J Med 2004;350:2438-40.

5. Yusuf S, Hawken S, Ounpuu S, et al. Effect of potentially modifiable risk factors associated with myocardial infarction in 52 countries (the INTERHEART study): case-control study. Lancet 2004;364:937-52.

6. King-Shier K, Quan H, Kapral MK, et al. Acute coronary syndromes presentations and care outcomes in Caucasian, South Asian and Chinese patients: a cohort study. BMJ Open 2019;9:e022479.

7. Kanaya AM, Wassel CL, Mathur D, et al. Prevalence and correlates of diabetes in South Asian Indians in the United States: findings from the metabolic syndrome and atherosclerosis in South Asians living in America study and the multi-ethnic study of atherosclerosis. Metab Syndr Relat Disord 2010;8:157-64.

8. Chiu M, Austin PC, Manuel DG, Tu JV. Comparison of cardiovascular risk profiles among ethnic groups using population health surveys between 1996 and 2007. CMAJ 2010;182:E301-10.

9. Khan NA, Wang H, Anand S, et al. Ethnicity and sex affect diabetes incidence and outcomes. Diabetes Care 2011;34:96-101.

10. Creatore MI, Moineddin R, Booth G, et al. Age- and sex-related prevalence of diabetes mellitus among immigrants to Ontario, Canada. CMAJ 2010;182:781-9.

11. Tu JV, Chu A, Donovan LR, et al. The Cardiovascular Health in Ambulatory Care Research Team (CANHEART): using big data to measure and improve cardiovascular health and healthcare services. Circ Cardiovasc Qual Outcomes 2015;8:204-12.

12. Banerjee AT, Shah BR. Differences in prevalence of diabetes among immigrants to Canada from South Asian countries. Diabet Med 2018;35: $937-43$. 
13. Whincup PH, Gilg JA, Papacosta O, et al. Early evidence of ethnic differences in cardiovascular risk: cross sectional comparison of British South Asian and white children. BMJ 2002;324:635.

14. Petersen KF, Dufour S, Feng J, et al. Increased prevalence of insulin resistance and nonalcoholic fatty liver disease in Asian-Indian men. Proc Natl Acad Sci U S A 2006;103:18273-7.

15. Motala AA, Omar MA. Evidence for impaired pancreatic beta cell function in South African Indians with impaired glucose tolerance. Diabet Med 1994;11:437-44.

16. Sohani ZN, Deng WQ, Pare G, et al. Does genetic heterogeneity account for the divergent risk of type 2 diabetes in South Asian and white European populations? Diabetologia 2014;57:2270-81.

17. Bhopal R, Unwin N, White M, et al. Heterogeneity of coronary heart disease risk factors in Indian, Pakistani, Bangladeshi, and European origin populations: cross sectional study. BMJ 1999;319:215-20.

18. Proudler AJ, Godsland IF, Bruce R, Seed M, Wynn V. Lipid and carbohydrate metabolic risk markers for coronary heart disease and blood pressure in healthy non-obese premenopausal women of different racial origins in the United Kingdom. Metabolism 1996;45:328-33.

19. Karthikeyan G, Teo KK, Islam S, et al. Lipid profile, plasma apolipoproteins, and risk of a first myocardial infarction among Asians: an analysis from the INTERHEART Study. J Am Coll Cardiol 2009;53: $244-53$.

20. Sanghera DK, Hopkins R, Malone-Perez MW, et al. Targeted sequencing of candidate genes of dyslipidemia in Punjabi Sikhs: population-specific rare variants in GCKR promote ectopic fat deposition. PLoS One 2019;14:e0211661.

21. Raygor V, Abbasi F, Lazzeroni LC, et al. Impact of race/ethnicity on insulin resistance and hypertriglyceridaemia. Diab Vasc Dis Res 2019;16: 153-9.

22. Chow CK, McQuillan B, Raju PK, et al. Greater adverse effects of cholesterol and diabetes on carotid intima-media thickness in South Asian Indians: comparison of risk factor-IMT associations in two population-based surveys. Atherosclerosis 2008;199:116-22.

23. Anand SS, Yusuf S, Vuksan V, et al. Differences in risk factors, atherosclerosis and cardiovascular disease between ethnic groups in Canada: the study of health assessment and risk in ethnic groups (SHARE). Indian Heart J 2000;52:S35-43.

24. Tu JV, Chu A, Rezai MR, et al. The Incidence of Major Cardiovascular Events in Immigrants to Ontario, Canada: The CANHEART Immigrant Study. Circulation 2015;132:1549-59.

25. Eapen D, Kalra GL, Merchant N, Arora A, Khan BV. Metabolic syndrome and cardiovascular disease in South Asians. Vasc Health Risk Manag 2009;5:731-43.

26. Misra A, Vikram NK. Insulin resistance syndrome (metabolic syndrome) and obesity in Asian Indians: evidence and implications. Nutrition 2004;20:482-91.

27. Jih J, Mukherjea A, Vittinghoff E, et al. Using appropriate body mass index cut points for overweight and obesity among Asian Americans. Prev Med 2014;65:1-6.

28. Kapoor N, Furler J, Paul TV, Thomas N, Oldenburg B. Normal weight obesity: an underrecognized problem in individuals of South Asian descent. Clin Ther 2019;41:1638-42.

29. Snehalatha C, Viswanathan V, Ramachandran A. Cutoff values for normal anthropometric variables in Asian Indian adults. Diabetes Care 2003;26:1380-4.
30. Hsu WC, Araneta MR, Kanaya AM, Chiang JL, Fujimoto W. BMI cut points to identify at-risk Asian Americans for type 2 diabetes screening. Diabetes Care 2015;38:150-8.

31. Quan H, Chen G, Walker RL, et al. Incidence, cardiovascular complications and mortality of hypertension by sex and ethnicity. Heart 2013;99:715-21.

32. Rana A, de Souza RJ, Kandasamy S, Lear SA, Anand SS. Cardiovascular risk among South Asians living in Canada: a systematic review and metaanalysis. CMAJ Open 2014;2:E183-91.

33. Ediriweera DS, Dilina N, Perera U, Flores F, Samita S. Risk of low birth weight on adulthood hypertension - evidence from a tertiary care hospital in a South Asian country, Sri Lanka: a retrospective cohort study. BMC Public Health 2017;17:358.

34. Ormshaw NG, Junejo RT, Marshall JM. Forearm vasodilator responses to environmental stress and reactive hyperaemia are impaired in young South Asian men. Eur J Appl Physiol 2018.

35. Liu Q, Quan H, Chen G, Qian H, Khan N. Antihypertensive medication adherence and mortality according to ethnicity: a cohort study. Can J Cardiol 2014;30:925-31.

36. Brewster LM, van Montfrans GA, Oehlers GP, Seedat YK. Systematic review: antihypertensive drug therapy in patients of African and South Asian ethnicity. Intern Emerg Med 2016;11:355-74.

37. Nerenberg KA, Zarnke KB, Leung AA, et al. Hypertension Canada's 2018 Guidelines for Diagnosis, Risk Assessment, Prevention, and Treatment of Hypertension in Adults and Children. Can J Cardiol 2018;34:506-25.

38. Eastwood SV, Tillin T, Chaturvedi N, Hughes AD. Ethnic differences in associations between blood pressure and stroke in South Asian and European men. Hypertension 2015;66:481-8.

39. Wang J, Tillin T, Hughes AD, Chaturvedi N. Associations between family history and coronary artery calcium and coronary heart disease in British Europeans and South Asians. Int J Cardiol 2019 Aug 1 [Epub ahead of print].

40. Patel J, Al Rifai M, Cainzos-Achirica M, et al. Family history of CHD is associated with severe CAC in South Asians: comparing the MASALA and MESA Studies. JACC Cardiovasc Imaging 2017;10:958-60.

41. Jonnalagadda SS, Diwan S, Cohen DLUS. Food Guide Pyramid food group intake by Asian Indian immigrants in the U.S. J Nutr Health Aging 2005;9:226-31.

42. Ghai NR, Jacobsen SJ, Van Den Eeden SK, et al. A comparison of lifestyle and behavioral cardiovascular disease risk factors between Asian Indian and White non-Hispanic men. Ethn Dis 2012;22:168-74.

43. Johansson J, Carlson LA, Landou C, Hamsten A. High density lipoproteins and coronary atherosclerosis. A strong inverse relation with the largest particles is confined to normotriglyceridemic patients. Arterioscler Thromb 1991;11:174-82.

44. Bhalodkar NC, Blum S, Rana T, et al. Comparison of levels of large and small high-density lipoprotein cholesterol in Asian Indian men compared with Caucasian men in the Framingham Offspring Study. Am J Cardiol 2004;94:1561-3.

45. Lamon-Fava S, Jimenez D, Christian JC, et al. The NHLBI Twin Study: heritability of apolipoprotein A-I, B, and low density lipoprotein subclasses and concordance for lipoprotein(a). Atherosclerosis 1991;91: 97-106.

46. Austin MA, Sandholzer C, Selby JV, et al. Lipoprotein(a) in women twins: heritability and relationship to apolipoprotein(a) phenotypes. Am J Hum Genet 1992;51:829-40. 
47. Erqou S, Thompson A, Di Angelantonio E, et al. Apolipoprotein(a) isoforms and the risk of vascular disease: systematic review of 40 studies involving 58,000 participants. J Am Coll Cardiol 2010;55:2160-7.

48. Gambhir JK, Kaur H, Prabhu KM, Morrisett JD, Gambhir DS. Association between lipoprotein(a) levels, apo(a) isoforms and family history of premature CAD in young Asian Indians. Clin Biochem 2008;41: 453-8.

49. Lanktree MB, Anand SS, Yusuf S, Hegele RA. Comprehensive analysis of genomic variation in the LPA locus and its relationship to plasma lipoprotein(a) in South Asians, Chinese, and European Caucasians. Circ Cardiovasc Genet 2010;3:39-46.

50. Chopra V, Vasisht S, Gulati S, Manchanda SC. Serum levels of lipoprotein(a) and other lipids in angiographically defined coronary artery disease patients and healthy blood bank donors. Indian J Med Sci 2000;54:284-9.

51. Gambhir JK, Kaur H, Gambhir DS, Prabhu KM. Lipoprotein(a) as an independent risk factor for coronary artery disease in patients below 40 years of age. Indian Heart J 2000;52:411-5.

52. Gupta R, Vasisht S, Bahl VK, Wasir HS. Correlation of lipoprotein(a) to angiographically defined coronary artery disease in Indians. Int J Cardiol 1996;57:265-70.

53. Gupta R, Kastia S, Rastogi S, et al. Lipoprotein(a) in coronary heart disease: a case-control study. Indian Heart J 2000;52:407-10.

54. Isser HS, Puri VK, Narain VS, et al. Lipoprotein(a) and lipid levels in young patients with myocardial infarction and their first-degree relatives. Indian Heart J 2001;53:463-6.

55. Mohan V, Deepa R, Haranath SP, et al. Lipoprotein(a) is an independent risk factor for coronary artery disease in NIDDM patients in South India. Diabetes Care 1998;21:1819-23.

56. Bilen O, Kamal A, Virani SS. Lipoprotein abnormalities in South Asians and its association with cardiovascular disease: current state and future directions. World J Cardiol 2016;8:247-57.

57. Anand SS, Enas EA, Pogue J, et al. Elevated lipoprotein(a) levels in South Asians in North America. Metabolism 1998;47:182-4.

58. Saleheen D, Haycock PC, Zhao W, et al. Apolipoprotein(a) isoform size, lipoprotein(a) concentration, and coronary artery disease: a Mendelian randomisation analysis. Lancet Diabetes Endocrinol 2017;5:524-33.

59. Song C, Burgess S, Eicher JD, O’Donnell CJ, Johnson AD. Causal effect of plasminogen activator inhibitor type 1 on coronary heart disease. J Am Heart Assoc 2017;6.

60. Hughes K, Aw TC, Kuperan P, Choo M. Central obesity, insulin resistance, syndrome X, lipoprotein(a), and cardiovascular risk in Indians, Malays, and Chinese in Singapore. J Epidemiol Community Health 1997;51:394-9.

61. Deepa R, Mohan V, Premanand C, et al. Accelerated platelet activation in Asian Indians with diabetes and coronary artery disease-The Chennai Urban Population Study (CUPS-13). J Assoc Physicians India 2006;54: 704-8.

62. Chambers JC, Eda S, Bassett P, et al. C-reactive protein, insulin resistance, central obesity, and coronary heart disease risk in Indian Asians from the United Kingdom compared with European whites. Circulation 2001;104:145-50.

63. Chambers JC, Abbott J, Zhang W, et al. The South Asian genome. PloS One 2014;9:e102645.
64. Kooner JS, Saleheen D, Sim X, et al. Genome-wide association study in individuals of South Asian ancestry identifies six new type 2 diabetes susceptibility loci. Nat Genet 2011;43:984-9.

65. Joseph PG, Pare G, Asma S, et al. Impact of a genetic risk score on myocardial infarction risk across different ethnic populations. Can J Cardiol 2016;32:1440-6.

66. Morris AP, Voight BF, Teslovich TM, et al. Large-scale association analysis provides insights into the genetic architecture and pathophysiology of type 2 diabetes. Nat Genet 2012;44:981-90.

67. Mosca L, Benjamin EJ, Berra K, et al. Effectiveness-based guidelines for the prevention of cardiovascular disease in women-2011 update: a guideline from the American Heart Association. J Am Coll Cardiol 2011;57:1404-23.

68. Yeung RO, Savu A, Kinniburgh B, et al. Prevalence of gestational diabetes among Chinese and South Asians: a Canadian population-based analysis. J Diabetes Complications 2017;31:529-36.

69. Mukerji G, Chiu M, Shah BR. Gestational diabetes mellitus and pregnancy outcomes among Chinese and South Asian women in Canada. J Matern Fetal Neonatal Med 2013;26:279-84.

70. Anand SS, Gupta M, Teo KK, et al. Causes and consequences of gestational diabetes in South Asians living in Canada: results from a prospective cohort study. CMAJ Open 2017;5:E604-11.

71. Gadgil MD, Oza-Frank R, Kandula NR, Kanaya AM. Type 2 diabetes after gestational diabetes mellitus in South Asian women in the United States. Diabetes Metab Res Rev 2017;33.

72. Shah BR, Retnakaran R, Booth GL. Increased risk of cardiovascular disease in young women following gestational diabetes mellitus. Diabetes Care 2008;31:1668-9.

73. Tobias DK, Stuart JJ, Li S, et al. Association of history of gestational diabetes with long-term cardiovascular disease risk in a large prospective cohort of US women. JAMA Intern Med 2017;177:1735-42.

74. Kaul P, Savu A, Nerenberg KA, et al. Impact of gestational diabetes mellitus and high maternal weight on the development of diabetes, hypertension and cardiovascular disease: a population-level analysis. Diabet Med 2015;32:164-73.

75. Gopal DP, Usher-Smith JA. Cardiovascular risk models for South Asian populations: a systematic review. Int J Public Health 2016;61:525-34.

76. Tillin T, Hughes AD, Whincup P, et al. Ethnicity and prediction of cardiovascular disease: performance of QRISK2 and Framingham scores in a U.K. tri-ethnic prospective cohort study (SABRE-Southall And Brent REvisited). Heart 2014;100:60-7.

77. Aarabi M, Jackson PR. Predicting coronary risk in UK South Asians: an adjustment method for Framingham-based tools. Eur J Cardiovasc Prev Rehabil 2005;12:46-51.

78. Hippisley-Cox J, Coupland C, Vinogradova Y, et al. Predicting cardiovascular risk in England and Wales: prospective derivation and validation of QRISK2. BMJ 2008;336:1475-82.

79. Kanaya AM, Vittinghoff E, Lin F, et al. Incidence and progression of coronary artery calcium in South Asians compared with 4 race/ethnic groups. J Am Heart Assoc 2019;8:e011053.

80. Yusuf S, Zhao F, Mehta SR, et al. Effects of clopidogrel in addition to aspirin in patients with acute coronary syndromes without ST-segment elevation. N Engl J Med 2001;345:494-502.

81. Wiviott SD, Braunwald E, McCabe $\mathrm{CH}$, et al. Prasugrel versus clopidogrel in patients with acute coronary syndromes. N Engl J Med 2007;357:2001-15. 
82. Wallentin L, Becker RC, Budaj A, et al. Ticagrelor versus clopidogrel in patients with acute coronary syndromes. N Engl J Med 2009;361: $1045-57$.

83. Chan M. Clopidogrel pharmacogenetics of east, south and other Asian populations. Eur Heart J Suppl 2012;14:A41-2.

84. Patel JV, Gupta S, Lie F, Hughes EA. Efficacy and safety of atorvastatin in South Asian patients with dyslipidemia: an open label noncomparative pilot study. Vasc Health Risk Manag 2005;1:351-6.

85. Jayaram S, Jain MM, Naikawadi AA, Gawde A, Desai A. Comparative evaluation of the efficacy, safety, and tolerability of rosuvastatin $10 \mathrm{mg}$ with atorvastatin $10 \mathrm{mg}$ in adult patients with hypercholesterolaemia: the first Indian study. J Indian Med Assoc 2004;102:48-50. 2.

86. Kaila KS, Norris CM, Graham MM, Ali I, Bainey KR. Long-term survival with revascularization in South Asians admitted with an acute coronary syndrome (from the Alberta Provincial Project for Outcomes Assessment in Coronary Heart Disease Registry). Am J Cardiol 2014;114:395-400.

87. Khan NA, Grubisic M, Hemmelgarn B, et al. Outcomes after acute myocardial infarction in South Asian, Chinese, and white patients. Circulation 2010;122:1570-7.

88. Quan H, Khan N, Li B, et al. Invasive cardiac procedure use and mortality among South Asian and Chinese Canadians with coronary artery disease. Can J Cardiol 2010;26:e236-42.

89. Deb S, Tu JV, Austin PC, et al. Impact of South Asian ethnicity on longterm outcomes after coronary artery bypass grafting surgery: a large population-based propensity matched study. J Am Heart Assoc 2016;5.
90. Sharma R, Norris CM, Gyenes G, Senaratne M, Bainey KR. Effect of cardiac rehabilitation on South Asian individuals with cardiovascular disease: results from the APPROACH Registry. Can J Cardiol 2016;32: S397-402.

91. Albalawi H, Coulter E, Ghouri N, Paul L. The effectiveness of structured exercise in the south Asian population with type 2 diabetes: a systematic review. Phys Sportsmed 2017;45:408-17.

92. Ramachandran A, Snehalatha C, Mary S, et al. The Indian Diabetes Prevention Programme shows that lifestyle modification and metformin prevent type 2 diabetes in Asian Indian subjects with impaired glucose tolerance (IDPP-1). Diabetologia 2006;49:289-97.

93. Bhatnagar P, Townsend N, Shaw A, Foster C. The physical activity profiles of South Asian ethnic groups in England. J Epidemiol Community Health 2016;70:602-8.

94. Natesan A, Nimbal VC, Ivey SL, et al. Engaging South Asian women with type 2 diabetes in a culturally relevant exercise intervention: a randomized controlled trial. BMJ Open Diabetes Res Care 2015;3: e000126.

95. Volgman AS, Palaniappan LS, Aggarwal NT, et al. Atherosclerotic Cardiovascular disease in South Asians in the United States: epidemiology, risk factors, and treatments: A Scientific Statement From the American Heart Association. Circulation 2018;138:e1-34.

96. Cainzos-Achirica M, Fedeli U, Sattar N, et al. Epidemiology, risk factors, and opportunities for prevention of cardiovascular disease in individuals of South Asian ethnicity living in Europe. Atherosclerosis 2019;286: 105-13. 